\title{
POTENSI EKSTRAK BUAH JAMBU JAMBLANG (Syzygium cumini L.Skeel) SEBAGAI ANTIOKSIDAN DAN TABIR SURYA
}

\author{
Widyastuti ${ }^{1 *}$, Najmi Hilaliyati ${ }^{2}$, Suci Intan Nisa Rahmi ${ }^{3}$ \\ 1,3 Prodi Farmasi, Universitas Perintis Indonesia \\ ${ }^{2}$ Sekolah Tinggi Ilmu Farmasi Padang
}

\section{Info Article}

Submitted :

23 September 2020

\section{Revised :}

21 Januari 2021

\section{Accepted :}

23 Januari 2021

\section{Corresponding Author :}

Widyastuti

\section{Email :}

rettyhandayani@gmail.com

\begin{abstract}
ABSTRAK
Penggunaan herbal saat ini semakin berkembang sebagai nutrifood, obat-obatan dan kosmetik. Syzigium cumini atau jambu jamblang mengandung senyawa yang mempunyai aktivitas sebagai antioksidan. Disamping itu adanya senyawa fenol didalam buah jambu jamblang diduga memiliki aktivitas tabir surya. Peelitian ini bertujuan untuk mengetahui aktivitas antioksidan dan tabir surya pada buah jambu jamblang dengan menggunakan pelarut yang berbeda, sehingga dapat dilihat potensi ekstrak sebagai antioksidan dan tabir surya. Ekstraksi buah jambu jamblang secara maserasi menggunakan pelarut etanol, etil asetat dan n-heksan. Ekstrak yang didapat dilakukan pemeriksaan kandungan senyawa metabolit sekunder. Pengujian aktivitas antioksidan menggunakan metode DPPH. Aktivitas tabir surya dilakukan secara metode spektrofotometri. Dari penelitian yag dilakukan didapatkan hasil ekstrak etanol mengandung senyawa alkaloid, flavonoid, fenolik dan terpenoid. Ekstrak etil asetat mengandung senyawa alkaloid dan terpenoid. Ekstrak n-heksan mengandung senyawa alkaloid. Nilai IC50 ekstrak etanol, etil asetat dan n-heksan masing-masing 4441,6 ppm, 1754,2 ppm dan 16964,6 ppm. Nilai Sun Protecting Factor (SPF) dari ekstrak etanol, etil asetat dan n-heksan pada kadar 1000 ppm masing-masing 6,$324 ; 38,018$ dan 3,872. Ekstrak etil asetat memiliki potensi sebagai antioksidan dan tabir surya yang lebih baik dibanding ekstrak etanol dan n-heksan.
\end{abstract}

Kata kunci: Syzigium cumini, Antioksidan, Tabir surya, SPF

Access this article

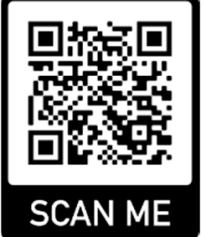

\section{ABSTRACT}

$\mathrm{L}$ The use of herbs is now growing as nutrifood, medicine and cosmetics. Syzigium cumini or guava contains compounds that have antioxidant activity. In addition, the presence of phenolic compounds in guava fruit is thought to have sunscreen activity. This study aims to determine the antioxidant and sunscreen activity of jamblang guava (Syzigium cumini (L.) Skeel) using different solvents, so that it can be seen the potential of the extract as an antioxidant and sunscreen. Maceration of guava fruit extraction using ethanol solvent, ethyl acetate and n-hexane. The extract obtained was examined for the content of secondary metabolite compounds. Antioxidant activity testing used the DPPH method. Sunscreen activity was carried out using the 
spectrophotometric method. From the research conducted, it was found that the ethanol extract contained alkaloid, flavonoid, phenolic, and terpenoid compounds. Ethyl acetate extract contains alkaloid and terpenoid compounds. N-hexane extract contains alkaloid compounds. The IC50 values of ethanol, ethyl acetate and n-hexane extract were respectively $4441.6 \mathrm{ppm}, 1754.2 \mathrm{ppm}$ and $16964.6 \mathrm{ppm}$. Sun Protecting Factor (SPF) values of ethanol, ethyl acetate and $n$-hexane extract at levels of 1000 ppm were 6.324 each; 38,018 and 3,872. Ethyl acetate extract has better potential as an antioxidant and sunscreen than ethanol and n-hexane extracts. Keywords: Syzigium cumini, Antioxidant, Sunscreen, SPF

\section{PENDAHULUAN}

Penggunaan herbal saat ini semakin berkembang sebagai obat-obatan dan kosmetik. Syzigium cumini atau jambu jamblang mengandung senyawa tannin yang bersifat mengecilkan pori-pori kulit sehingga dapat mengatasi jerawat dan kondisi kerusakan kulit lainnya, disamping mempunyai efek sebagai antioksidan (Parate et.al., 2019). Bagian tanaman (kulit kayu, daun, buah dan biji) mengandung senyawa asam galat, asam sitrat, asam malat, tanin, glikosida sianidin, flavonoid dan minyak esensial yang berbeda kadarnya pada masing-masing bagian tersebut (Ramya et.al., 2012). Kandungan antosianin dan senyawa fenolik di dalam buah jambu jamblang berpotensi sebagai antioksidan (Singh et.al., 2013).

Ekstrak etanol daun, biji dan batang S. cumini mempunyai aktivitas sebagai antioksidan dibandingkan dengan ekstrak airnya (Zahra et al., 2019). Ekstrak etanol buah mempunyai aktivitas antioksidan dengan menggunakan metode DPPH (Singh et al., 2013). Ekstrak air buah S. cumini memiliki aktivitas antioksidan secara in vivo pada tikus diabetes (Rekha et.al., 2008). Ekstrak aseton:air (7:3) mengandung tanin dari buah $S$. cumini menunjukkan aktivitas antioksidan yang sangat baik menggunakan metode DPPH dan FRAP (Zhang dan Lin, 2009).
Antioksidan yang terkandung di dalam buah jambu jamblang dapat menangkal radikal bebas pada kulit yang salah satunya disebabkan radiasi sinar ultraviolet (UV). Paparan radiasi UV yang lama meningkatkan risiko penyakit kulit seperti kanker dan reaksi fotoalergi. Radiasi UV-B (280-320 nm) terutama bertanggung jawab untuk memicu masalah kulit. Perlindungan kulit adalah metode yang cocok untuk melawan kerusakan akibat radiasi ultraviolet. Berbagai agen sintetis telah digunakan sebagai pelindung kulit terhadap sinar UV, tetapi karena potensi toksisitasnya pada manusia, penggunaannya terbatas.

Senyawa alam dianggap sebagai sumber tabir surya potensial karena penyerapannya di wilayah UV dan adanya aktivitas antioksidan (Korac dan Khambholja, 2011). Adanya korelasi yang baik ditemukan antara SPF dan kandungan fenolik, tetapi tidak ditemukan korelasi antara SPF dan kandungan flavonoid atau aktivitas antioksidan (Ebrahimzadehi et al., 2014). Dengan adanya kandungan senyawa fenolik pada buah jambu jamblang, diduga juga mempunyai aktivitas sebagai tabir surya. Penelitian yang dilakukan bertujuan untuk mengetahui aktivitas antioksidan dan tabir surya pada buah jambu jamblang (Syzigium cumini (L.) Skeel) dengan 
menggunakan pelarut yang berbeda, sehingga dapat dilihat potensi ekstrak dari pelarut yang memiliki aktivitas antioksidan dan tabir surya terbaik.

\section{METODE PENELITIAN}

\subsection{Alat dan Bahan}

Alat yang digunakan Spektrofotometer UV-Vis Shimadzu, rotary evaporator, timbangan digital (Ohaus), oven (Memmert) dan alat-alat gelas. Bahan yang digunakan etanol 96\% (brataco), etil asetat (brataco), n-heksan (brataco), metanol (merck), aquadest, $\mathrm{NH}_{4} \mathrm{OH}$ (merck), kloroform (merck), serbuk $\mathrm{Mg}$ (merck), $\mathrm{HCl}$ (brataco), $\mathrm{FeCl}_{3}$ (merck), $\mathrm{H}_{2} \mathrm{SO}_{4}$ (brataco), pereaksi Mayer, asam asetat anhidrat (merck), DPPH (merck) dan vitamin C (merck).

\subsection{Ekstraksi Buah Jambu Jamblang}

Buah jambu jamblang diperoleh dari daerah Rambatan Kabupaten Tanah Datar dan dilakukan identifikasi pada Herbarium Universitas Andalas Buah jambu jamblang segar dibuang biji buahnya, setiap $250 \mathrm{~g}$ daging buah dimaserasi masing-masing menggunakan pelarut etanol $96 \%$, etil asetat dan $\mathrm{n}$-heksan. Maserasi dihentikan bila pelarut telah bening. Hasil maserasi dipekatkan menggunakan rotary evaporator, sehingga diperoleh masingmasing ekstrak kental tiap-tiap pelarut.

\subsection{Pengujian Ekstrak}

Tiap ekstrak kental yang didapat dilakukan pemeriksaan skrining fitokimia meliputi uji alkaloid, flavonoid, fenolik, saponin, terpenoid dan steroid. masingmasing ekstrak ditimbang 2 gram pada wadah yang terpisah, lalu dibasakan dengan $\mathrm{NH}_{4} \mathrm{OH}$, kemudian tambahkan klorofom : air suling (1:1) $10 \mathrm{ml}$ masingmasing kocok dalam tabung reaksi, biarkan sejenak hingga terbentuk dua lapisan. Lapisan air untuk pemeriksaan (flavonoid, fenolik dan saponin), lapisan kloroform untuk pemeriksaan (terpenoid, steroid dan alkaloid).

\subsection{Pengujian Antioksidan Ekstrak}

Penentuan panjang gelombang serapan maksimum DPPH dengan konsentrasi 35 ppm. Serapan larutan diukur dengan alat spektrofotometer UVVis pada panjang gelombang 400 - 600 $\mathrm{nm}$. Larutan uji dibuat dengan konsentrasi ekstrak etanol 2500, 3000, 3500, 4000 dan $4500 \mathrm{ppm}$. Konsentrasi ekstrak etil asetat 1200, 1400, 1600, 1800 dan 2000 ppm. Konsentrasi ekstrak n-heksan 1000, 1500, 2000, 2500 dan 3000 ppm. Sebagai kontrol pembanding digunakan vitamin $\mathrm{C}$ dengan konsentrasi 10, 20, 30, 40 dan 50 ppm. Larutan uji masing-masing dipipet, ditambah larutan DPPH 35 ppm, diamkan 30 menit ditempat gelap. Ukur absorbansi padang panjang gelombang maksimum yang didapat. Tentukan persentase inhibisi dan nilai $I_{50}$ masing-masing ekstrak dan kontrol pembanding (Molyneux, 2004).

\subsection{Pengujian Aktivitas Tabir Surya}

Penentuan persentase transmisi eritema dan pigmentasi dimana masingmasing larutan uji dengan konsentrasi 1000 ppm diukur serapannya menggunakan Spektrofotometer UV-Vis pada panjang gelombang yang dapat menimbulkan eritema yaitu 292,5 - 337,5 $\mathrm{nm}$ dan pigmentasi 292,5 - 372,5 nm. Penentuan nilai Sun Protecting Factor (SPF) dimana masing-masing larutan diukur absorbansinya pada panjang gelombang 290 - 320. Dari data persentase eritema, persentase pigmentasi dan SPF, dapat ditentukan aktivitas tabir surya ekstrak (Widyastuti et al., 2016). 


\section{HASIL DAN PEMBAHASAN}

Buah jambu jamblang yang digunakan merupakan spesies Syzygium cumini (L.) Skeels. Penyarian sampel dilakukan dengan metode maserasi, karena kandungan antioksidan merupakan kandungan senyawa yang tidak tahan panas dan dapat menghindari rusaknya senyawa-senyawa yang bersifat termolabil sehingga metode maserasi dipilih pada penelitian ini. Pelarut yang digunakan adalah etanol, etil asetat dan n-heksan, tujuan penggunaan tiga pelarut dengan polaritas yang berbeda adalah untuk mengetahui rendemen dan mendapatkan aktivitas dari daging buah jambu jamblang berdasarkan tingkat kepolarannya. Dari penelitian didapatkan rendemen ekstrak etanol sebesar $38,920 \%$, ekstrak etil asetat $3,436 \%$ dan ekstrak n-heksan 0,296\%.

Tabel 1. Uji Skrining Fitokimia

\begin{tabular}{lcccc}
\hline \multirow{2}{*}{ Metabolit sekunder } & Buah segar & \multicolumn{3}{c}{ Ekstrak } \\
\cline { 3 - 5 } & & Etanol & Etil asetat & N-heksan \\
\hline Alkaloid & + & + & + & + \\
Flavonoid & + & + & - & - \\
Fenolik & + & + & - & - \\
Saponin & - & - & - & - \\
Terpenoid & + & + & + & - \\
Steroid & - & - & - & - \\
\hline
\end{tabular}

Hasil uji skrining fitokimia yang dilakukan dapat dilihat pada Tabel 1. Terdapat perbedaan kandungan metabolit sekunder dari buah segar dengan setelah ekstraksi tergantung pelarut yang digunakan. Kandungan flavonoid dan fenolik terdapat pada buah segar dan ekstrak etanol, sedangkan pada ekstrak etil asetat dan $\mathrm{n}$-heksan tidak ditemukan adanya flavonoid dan fenolik. Semua ekstrak mengandung alkaloid. Terpenoid tidak terdapat pada ekstrak n-heksan. Hasil ini sama dengan yang didapatkan oleh Migliato et al., (2009), dimana ekstrak etanol buah S. cumini yang didapat secara perkolasi mengandung senyawa polifenol. Ekstrak buah yang didapatkan dengan cara freeze dried mengandung senyawa tannin, asam galat dan asam elagik (Zhang dan Lin, 2009). Ekstrak etanol buah S cumini mengandung senyawa antosianin dan fenolik (Singh et al., 2013). Secara keseluruhan buah S. cumini mengandung asam askorbat, antosianin, tannin dan senyawa fenol (Suradkar et al., 2017; Akhila dan Hiremath, 2018). Penelitian yang dilakukan oleh Rohadi et al., (2017) menunjukkan ektrak metanol buah $S$. cumini mengandung senyawa fenolik, asam galat, asam tanat dan rutin. Adanya alkaloid pada ekstrak juga disampaikan oleh Agarwal et al., (2019) dimana adanya kandungan alkaloid pada daun, biji buah, buah, bunga dan akar dari S. cumini dengan kadar yang berbeda.

Pemeriksaan antioksidan terhadap ekstrak buah jambu jamblang dilakukan dengan metode DPPH. Metode DPPH dipilih karena merupakan metode yang sederhana, mudah, peka dan hanya memerlukan sedikit sampel dengan waktu yang relatif singkat. Aktivitas antioksidan merupakan kemampuan suatu senyawa atau ekstrak untuk menghambat reaksi oksidasi yang dapat dinyatakan dengan persentase penghambatan atau 
persentase inhibisi. Parameter yang digunakan untuk menunjukkan aktivitas antioksidan adalah $\mathrm{IC}_{50}$ yang merupakan konsentrasi suatu zat antioksidan yang dapat menyebabkan 50\% DPPH kehilangan karakter radikal atau konsentrasi suatu zat antioksidan yang memberikan persentase penghambatan 50\% (Molyneux, 2004).
Panjang gelombang maksimum yang digunakan pada penelitian ini sebesar $515 \mathrm{~nm}$. Hasil penelitian aktivitas antioksidan dapat dilihat pada Tabel 2 dan Gambar 1. Dari kurva regresi didapatkan persamaan regresi untuk menghitung nilai $\mathrm{IC}_{50}$ masing-masing ekstrak dan vitamin $\mathrm{C}$ sebagai pembanding.
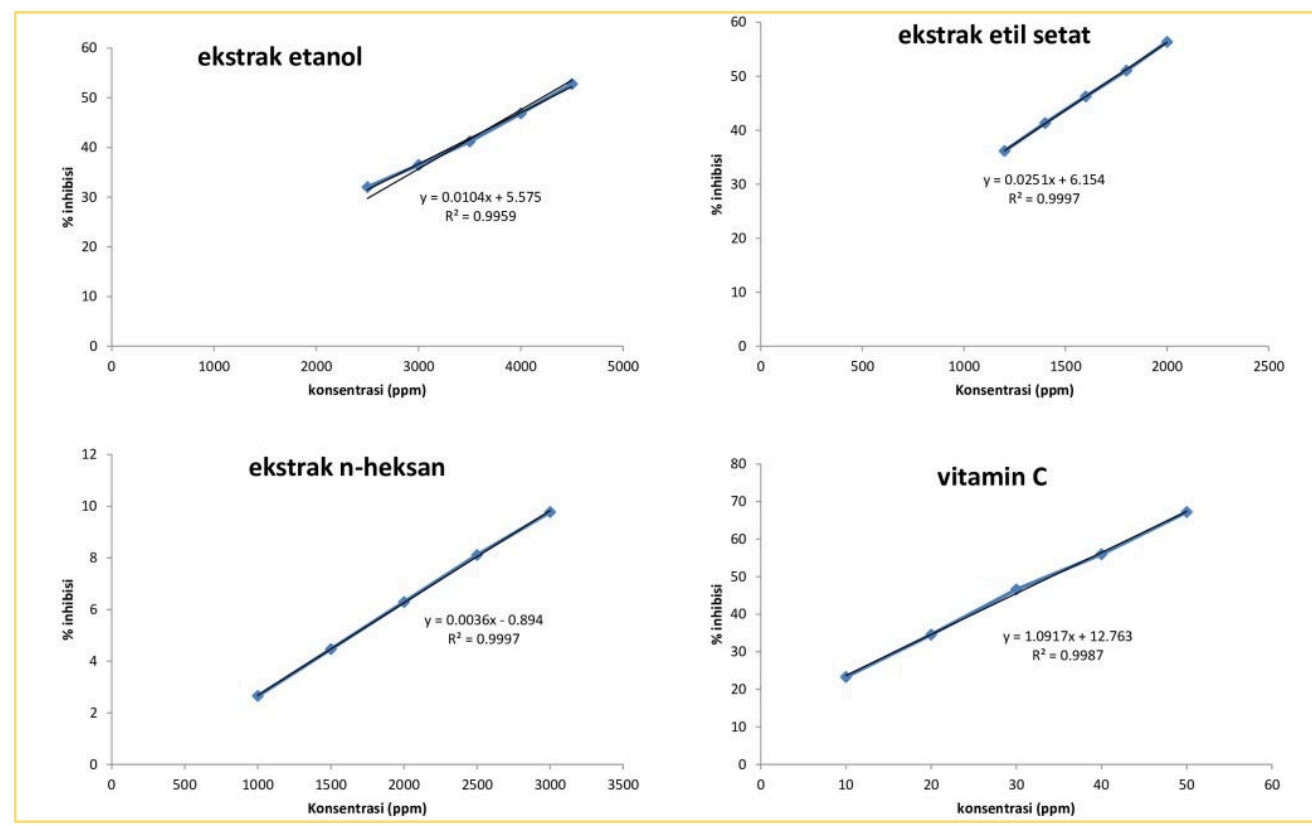

Gambar 1. Kurva Regresi Ekstrak dan Vitamin C

Hasil perhitungan nilai $I C_{50}$ yang didapat, diketahui bahwa aktivitas antioksidan pada ekstrak etil asetat lebih baik dari pada etanol dan n-heksan tapi lebih rendah aktivitas antioksidannya dari pada vitamin C. Ekstrak etil asetat memberikan pengaruh efektifitas yang tinggi sebagai antioksidan terhadap DPPH, dibanding ekstrak etanol dan n-heksan.

Tabel 2. Hasil Uji Efektivitas Lipbalm

\begin{tabular}{lcccc}
\hline \multicolumn{1}{c}{ Ekstrak } & Persamaan Regresi & $\mathbf{r}^{\mathbf{2}}$ & $\mathbf{I C}_{\mathbf{5 0}}$ & Kategori \\
\hline Etanol & $\mathrm{y}=0,0104 \mathrm{x}+5,575$ & 0,9959 & $4441,6 \mathrm{ppm}$ & Sangat lemah \\
Etil setat & $\mathrm{y}=0,0251 \mathrm{x}+6,154$ & 0,9997 & $1754,2 \mathrm{ppm}$ & Sangat lemah \\
N-heksan & $\mathrm{y}=0,0036 \mathrm{x}-0,894$ & 0,9997 & $16964,6 \mathrm{ppm}$ & Sangat lemah \\
Vitamin C & $\mathrm{y}=1,0917 \mathrm{x}+12,763$ & 0,9987 & $34,136 \mathrm{ppm}$ & Sangat kuat \\
\hline
\end{tabular}

Hasil yang didapat berbeda dengan yang dilakukan oleh Afify et al., (2011) dimana pada kadar 100 ppm ekstrak etanol, etil asetat dan n-heksan buah $S$. cumini memiliki kapasitas antioksidan masing-masing $81,81 \%, \quad 81,07 \%$ dan $34,41 \%$, ekstrak etanol memiliki kapasitas yang lebih baik dibandingkan ekstrak etil 
asetat. Penelitian lain didapatkan ekstrak etanol buah memiliki nilai IC 50 $_{50}$ sebesar 195 ppm (Singh et al., 2013). Ekstrak metanol buah dengan kadar 400 ppm, memiliki kapasitas antioksidan sebesar 93,05\% (Rohadi et al., 2017). Ekstrak buah yang didapatkan secara freeze dried memilik nilai $I_{50}$ sebesar 82,21 ppm (Zhang dan Lin, 2009) dan 319,89 ppm (Marliani dkk, 2014). Adanya perbedaan aktivitas antioksidan yang didapat kemungkinan karena berbedanya tempat tumbuh tanaman ini.

Adanya kandungan alkaloid pada ekstrak etil asetat juga mempengaruhi dari kekuatan antioksidan ekstrak dimana penelitian yang dilakukan oleh Gan et al., (2017) menunjukkan pada tanaman maca (Lepidium meyenii) efek antioksidan alkaloid lebih besar dibandingkan senyawa fenolik pada tanaman tersebut.

Efektivitas sediaan tabir surya dapat dilakukan dengan metode penentuan \% transmisi eritema (\%Te) dan \% transmisi pigmentasi (\%Tp). Transmisi merupakan persentase sinar yang diteruskan oleh sediaan tabir surya. Eritema adalah panjang gelombang yang dapat menimbulkan warna kemerahan pada kulit. Nilai transmisi eritema yaitu jumlah energi sinar ultraviolet penyebab eritema pada panjang gelombang 292,5 - 372,5 $\mathrm{nm}$, maka perhitungan nilai serapan untuk persentase eritema pada panjang gelombang tersebut. Pigmentasi adalah panjang gelombang yang dapat menimbulkan bintik hitam pada kulit. Nilai transmisi pigmentasi merupakan jumlah energi sinar ultraviolet penyebab pigmentasi pada panjang gelombang 292,5 - 372,5 nm, maka perhitungan nilai serapan untuk persentase pigmentasi pada panjang gelombang tersebut. Aktivitas tabir surya dapat dilihat dari pengukuran nilai SPF, \%Te dan \%Tp. Nilai SPF berkisar dari 0 - 100, semakin besar nilai SPF, maka sampel memiliki kemampuan yang lebih baik melindungi kulit dari paparan sinar UV. Hasil perhitungan \%Te, \%Tp dan SPF dapat dilihat pada Tabel 3.

Tabel 3. Kategori Penilaian Tabir Surya

\begin{tabular}{|c|c|c|c|c|c|}
\hline \multirow{2}{*}{$\begin{array}{c}\text { Ekstrak (1000 } \\
\text { ppm) }\end{array}$} & \multicolumn{2}{|c|}{ Persentase Transmisi } & \multirow{2}{*}{$\begin{array}{l}\text { Kategori } \\
\text { penilaian }\end{array}$} & \multirow{2}{*}{ Nilai SPF } & \multirow{2}{*}{ Kategori penilaian } \\
\hline & $\% \mathrm{Te}$ & $\%$ Tp & & & \\
\hline Etanol & 0,431 & 0,493 & total block & 6,324 & Proteksi ekstra \\
\hline Etil Asetat & 0,229 & 0,287 & total block & 38,018 & Proteksi ultra \\
\hline N-heksan & 0,556 & 0,621 & total block & 3,872 & Proteksi minimal \\
\hline
\end{tabular}

Nilai SPF yang baik dari suatu bahan tabir surya adalah diatas 15. Dari hasil yang didapat pada kadar 1000 ppm, ekstrak etil asetat telah menunjukkan nilai diatas 15 , sedangkan ekstrak etanol dan ekstrak nheksan masih dibawah nilai 15. Menurut \%Te dan \%Tp semua ekstrak masuk kedalam kategori total block dimana semua ekstrak dapat menghalangi efek negative sinar UVB pada kulit secara in vitro yang menyebabkan kulit kemerahan dan gelap. Karena itu potensi ekstrak etil asetat buah Syzigium cumini (L.) Skeel pada penelitian ini lebih baik dibandingkan ekstrak lain sebagai tabir surya dengan kadar yang sama. Disamping itu adanya kandungan senyawa alkaloid dan terpenoid pada ekstrak juga 
mempengaruhi aktivitas tabir surya hal ini sama dengan yang dilaporkan oleh Eff et al., (2018) dimana pada pengujian buah mahkota dewa (Phaleria marcocarpha (Scheff.) Boerl) yang mengandung alkaloid juga menunjukkan aktivitas sebagai tabir surya.

\section{KESIMPULAN}

Penelitian aktivitas antioksidan dan tabir surya dari ekstrak buah jambu jamblang menggunakan pelarut yang berbeda didapatkan ekstrak asetil asetat yang mengandung senyawa metabolit sekunder alkaloid dan terpenoid memiliki aktivitas antioksidan yang lebih baik dibandingkan ekstrak etanol dan n-heksan dengan nilai $I_{50}$ sebesar 1754,2 . Demikian pula dengan aktivitas tabir surya, ekstrak etil asetat pada kadar $1 \mathrm{mg} / \mathrm{mL}$ telah mempunyai nilai SPF sebesar 38,018 dan dikategorikan sebagai proteksi ultra, sehingga dapat disimpulkan ekstrak etil asetat buah jambu jamblang mempunyai aktivitas antioksidan dan tabir surya yang lebih baik dibandingkan ekstrak etanol dan n-heksan.

\section{DAFTAR PUSTAKA}

Afify, A. E. M. R., Fayed, S. A., Shalaby, E. A., \& El-shemy, H. A. (2011). Syzygium cumini (pomposia) active principles exhibit potent anticancer and antioxidant activities. African Journal of Pharmacy and Pharmacology, 5(7), 948-956.

Agarwal, P., Gaur, P. K., Tyagi, N., Puri, D., Kumar, N., \& Kumar, S. S. (2019). An overview of phytochemical, therapeutic, pharmacological and traditional importance of Syzygium cumini. Asian Journal of Pharmacognosy, 3(1), 5 - 17.

Akhila, H., \& Hiremath, U. S. (2018). Physicochemical properties of jamun (Syzygium cumini L.) fruits and its processed products. Int. J. Pure App. Biosci, 6(6), 1317-1325.
Ebrahimzadehi, M. A., Enayatifard, R., Khalili, M., Ghaffarloo, M., Saeedi, M., \& Charati, J. Y. (2014). Correlation between sun protection factor and antioxidant activity, phenol and flavonoid contents of some medicinal plants. Iranian Journal of Pharmaceutical Research, 13(3), 10411047.

Eff, A. R. Y., Pertiwi, R. D. Rakhmawati, I., \& Utami, T. P. (2018). In-vitro and in-vivo sunscreen activity of active compounds isolated from fruits of Phaleria marcocarpha (Scheff.) Boerl). J Young Pharm, 10(2), 106 - 110.

Gan, J., Feng, Y., He, Z., Li, X., \& Zhang, H. (2017). Correlations between antioxidant activity and alkaloids and phenols of maca (Lepidium meyenii). Journal of Food Quality, 2017(3185945), 1 $-10$.

Korac, R.R., \& Khambholja, K.M. (2011). Potential of herbs in skin protection from ultraviolet radiation. Pharmacognosy Reviews, 5(10), 164-173.

Marliani, L., Kusriani, H., \& Sari, N. I. (2014). Aktivitas antioksidan daun dan buah jamblang (Syzigium cumini L.) Skeel. Prosiding SNaPP Sains, Teknologi Dan Kesehatan, 4(1), 201-206.

Migliato, K. F., Carvalho, E. S. De, Vitor, L., Carlos, J., Mello, P. De, Baby, A. R., Salgado, N. (2009). Total polyphenols from Syzygium cumini (L.) Skeels fruit extract. Brazilian Journal of Pharmaceutical Sciences, 45(1), 121-126.

Molyneux, P. (2004). The use of the stable free radical diphenylpicrylhydrazyl ( DPPH ) for estimating antioxidant activity. Songklanakarin Journal of Science and Technology, 26(2), 211-219.

Parate, M. A., Bajpai, N. D., \& Walke, D. D. (2019). Role of Syzygium cumini (jamun) in cosmetic. International Journal of Scientific Development and Research, 4(6), 193-201.

Ramya, S., Neethirajan, K., \& Jayakumararaj, R. (2012). Profile of bioactive compounds in Syzygium cumini - a review. Journal of 
Pharmacy Research, 5(8), 4548-4553.

Rekha, N., Balaji, R., \& Deecaraman, M. (2008). Effect of aqueous extract of Syzygium cumini pulp on antioxidant defense system in streptozotocin induced diabetic rats. Iranian Journal of Pharmacology \& Therapeutics, 7(2), 137145.

Rohadi, Santoso, U., Raharjo, S., \& Falah, I. I. (2017). Determination of antioxidant activity and phenolic compounds of methanolic extract of java plum (Syzygium cumini Linn.) seed. Indonesian Food and Nutrition Progress, 14(1), 9-20.

Singh, J., Shukla, R. K., \& Walia, S. (2013). Sugar profile, total phenolic and antioxidant potential of anthocyanins rich Syzygium cumini fruit. Natural Products An Indian Journal, 9(9), 350-354.

Suradkar, N., Pawar, V., \& Shere, D. (2017). bioactive composition of jamun (Syzygium cuminii L .) fruit. International Journal of Chemical Studies, 5(3), 470472.

Widyastuti., Kusuma, A.K., Nurlaili., \& Sukmawati, F. (2016). Aktivitas antioksidan dan tabir surya ekstrak etanol daun stroberi (Fragaria $x$ ananassa A.N. Duchesne). Jurnal Sains Farmasi \& Klinis, 3(1), 19 - 24.

Zahra, N., Nadir, M., Malik, A., Shaukat, A., Parveen, A., \& Tariq, M. (2019). In vitro phytochemical screening and antioxidant activity of jamun (Eugenia jambolana Linn) plants parts collected from Lahore, Pakistan. Biochemistry and Modern Applications, 2(1), 20-23.

Zhang, L. L., \& Lin, Y. M. (2009). Antioxidant tannins from Syzygium cumini fruit. African Journal of Biotechnology, 8(10), 2301-2309. Physicochemical,

proximate and

Copyright $\odot 2020$ The author(s). You are free to Share - copy and redistribute the material in any medium or format. Adapt — remix, transform, and build upon the material. manner, but not in any way that suggests the licensor endorses you or your use. NonCommercial - You may not use the material for commercial purposes. ShareAlike - If you remix, transform, or build upon the material, you must distribute your contributions under the same license as the original. No additional restrictions - You may not apply legal terms or technological measures that legally restrict others from doing anything the license permits. 